\title{
Changes in alpine wetland ecosystems of the Qinghai-Tibetan plateau from 1967 to 2004
}

\author{
Yu Zhang • Genxu Wang • Yibo Wang
}

Received: 14 June 2010 / Accepted: 9 November 2010 / Published online: 9 December 2010

(C) The Author(s) 2010. This article is published with open access at Springerlink.com

\begin{abstract}
Spatiotemporal shifts in the extent and distribution of alpine wetland ecosystems in China's Qinghai-Tibet plateau were investigated for the period 1967-2004. Using aerial photographs for 1967, and satellite remote sensing data for 1986, 2000, and 2004/5, the main components and distribution of alpine wetland ecosystems in the headwaters regions of the Yangtze and Yellow Rivers, as well as those of the nearby Zoige region, were analyzed. Widespread degradation of the Qinghai-Tibet plateau's alpine wetlands occurred between 1967 and 2004, with over $10 \%$ of their area being lost. The greatest such degradation occurred in the headwaters region of Yangtze River, where wetland areas shrank by $29 \%$, and the area of dried-up lakes rose by $17.5 \%$. In the Yellow River's headwaters region as well as the Zoige region, wetland ecosystems clearly underwent accelerated fragmentation and isolation in their spatial distribution. The wetlands' degradation was closely correlated to the
\end{abstract}

Y. Zhang · G. Wang · Y. Wang

College of Resources and Environment,

Lanzhou University, Lanzhou 730000,

People's Republic of China

G. Wang $(\varangle)$

Institute of Mountain Hazards and Environment,

Chinese Academy of Sciences, Chengdu,

610041, People's Republic of China

e-mail: wanggx@imde.ac.cn rise in air temperature, which from 1982-2004 was over 2-fold faster that from 1965-1982.

Keywords Alpine wetland - Dynamical change • Spatial pattern $\cdot$ Hydro-ecological function . Qinghai-Tibetan plateau

\section{Introduction}

Wetlands ecosystems, bearing traits of both terrestrial and aquatic ecosystems, have important global ecological functions. Their abundant biodiversity and large water conservation and storage capacities distinguish them from other terrestrial and aquatic ecosystems (Bullock and Acreman 2003). Hydrological conditions determine a wetland's attributes and spatial layout, while conversely, wetlands influence a region's water cycle and a basin's hydrological processes (Price and Schlotzhauer 1999; Price and Waddington 2000; Reeve et al. 2000). The mechanisms by which wetland ecosystems and hydrological processes mutually interact have long attracted the attention of ecologists and hydrologists. The response mechanisms of wetland ecosystems to hydrological changes at different scales has been established (Wassen and Grootjans 1996; Rodriguez-Iturbe 2000; Price et al. 2005).

Global climate change has significantly affected natural ecosystems around the world, particularly 
wetland ecosystems, whose sensitivity to global climate changes has accelerated their degradation (Wassen and Grootjans 1996; Rodriguez-Iturbe 2000; Bullock and Acreman 2003). Studies of Arctic frost wetland ecosystems have shown the cryosphere to be highly sensitive to global temperature changes and their effects on permafrost (Conly and Van Der Kamp 2001; Quinton and Marsh 1999). The changes in frost wetland ecosystems under such conditions have led to dramatic shifts in such regions' soil properties, water cycle, and soil $\mathrm{CO}_{2}$ emissions, as well as profoundly affecting other regional systems (Quinton and Marsh 1999; Jorgenson et al. 2001; McGuire et al. 2003; DeFries and Eshleman 2004).

Located in the hinterland of the QinghaiTibetan plateau, the headwaters regions of the Yangtze and Yellow Rivers house the largest frost wetlands in China. The Zoige wetland, located in the northeastern portion of the Qinghai-Tibetan plateau, represents the largest peatland in China (Lang 1999). These three wetlands represent over $85 \%$ of alpine wetland areas in the QinghaiTibetan plateau region and form the largest lower latitude alpine wetland in the world. As with Arctic permafrost wetlands, alpine wetlands are quite sensitive to global climate changes (Jorgenson et al. 2001; Wang et al. 2001; An 2003; McGuire et al. 2003). Making up the majority of China's swamp wetland, alpine wetland systems are dominated by alpine swamp wetland and frost lake wetland types (Lang 1999; An 2003; Gong et al. 2010). Given the push to protect the plateau's biodiversity and implement water conservation measures in the headwaters region of the Yangtze and Yellow Rivers, what has happened to alpine wetland ecosystems under the last 40 years' climatic changes and how such ecological changes have impacted upon the headwaters' hydrological processes are important considerations.

Over the last 50 years, climate change in the Qinghai-Tibetan plateau has largely paralleled that of the whole country, where air temperatures have risen by $0.4-0.6^{\circ} \mathrm{C} \mathrm{decade}^{-1}$ (Qin 2002). However, within the Qinghai-Tibetan plateau, air temperatures have risen somewhat more sharply, particularly in the headwaters regions of the Yangtze and Yellow rivers (Wang et al. 2001; $\mathrm{Li}$ and $\mathrm{Wu} 2005)$. Consequently, changes in the plateau's unique alpine wetland ecosystems have become a matter of common concern to both ecologists and hydrologists. However, few studies have documented the change in extent and distribution of alpine wetland ecosystems under climatic changes and its influence on hydrological processes (He and Zhao 2000; Zhou 2001; Wang et al. 2007a, b). While the spatial pattern of wetland ecosystems is known to have an important effect on hydrological and biological processes (Price et al. 2005; Cui and Yang 2006), the link between changes in wetland ecosystems and river hydrological processes has not been adequately quantified. Consequently, the main purpose of this study was to explore changes (1967-2004) in both the Qinghai-Tibetan plateau's alpine wetland ecosystems and their influence on surface hydrological processes. More specifically, we sought to address the following questions: (1) what spatiotemporal shifts in alpine wetland ecosystem extent, distribution, and condition have occurred under the climatic changes? (2) how do these changes correlate with climatic change? and (3) how do these changes affect the hydrological processes of the region's rivers?

\section{Data and methods}

\section{Study area}

The headwaters portion of the Yangtze River watershed has an area of $13.78 \times 10^{4} \mathrm{~km}^{2}$ and lies between $90^{\circ} 43^{\prime}-96^{\circ} 45^{\prime} \mathrm{E}$ and $32^{\circ} 30^{\prime}-35^{\circ} 35^{\prime} \mathrm{N}$, while that of the Yellow River at $6.48 \times 10^{4} \mathrm{~km}^{2}$ lies between $33^{\circ} 00^{\prime}-35^{\circ} 35^{\prime} \mathrm{N}$ and $96^{\circ} 00^{\prime}-99^{\circ} 45^{\prime} \mathrm{E}$ (Fig. 1). The region's landforms are dominated by tall hills and a well-developed network of watercourses. The region's main naturally occurring alpine ecosystems are grassland, meadow, and swamp-wetland. Sparse alpine Myricaria shrub cover occurs locally in river valleys and provides sparse anti-erosive cover on upper mountain and scree slopes (Li and Zhou 1998; Wang et al. 2001). The Yangtze and Yellow rivers' headwaters, located in a transitional region between alpine semiarid and subhumid climatic zones, are characterized by a mean annual temperature of $-1.3^{\circ} \mathrm{C}$ to $-5.5^{\circ} \mathrm{C}$ and a mean annual precipitation of 


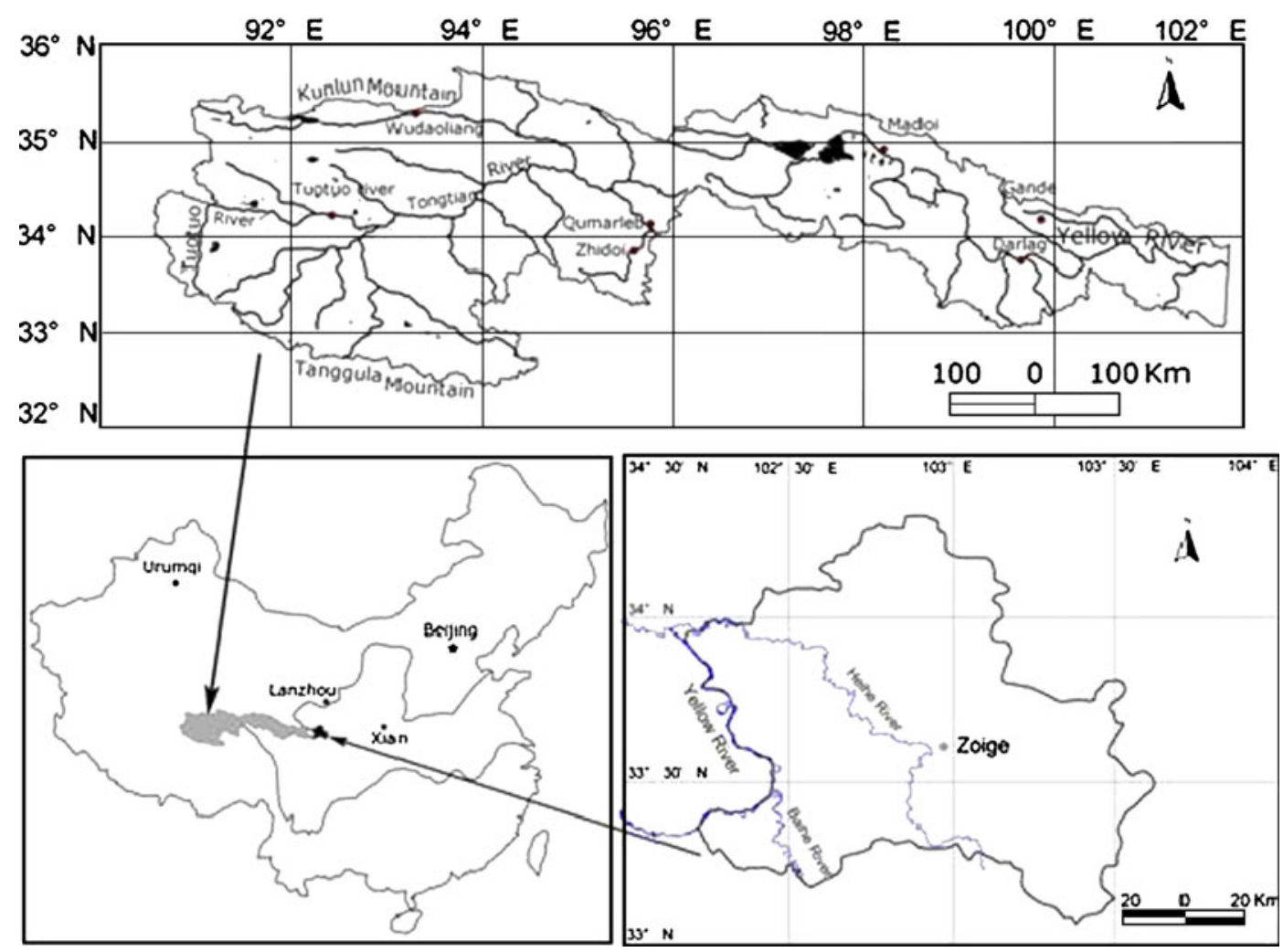

Fig. 1 Location of study

270-540 mm (Wang et al. 2001, 2006a, b). The Zoige wetland, listed among China's "important wetlands," is located between $102^{\circ} 8^{\prime}-103^{\circ} 36^{\prime} 48^{\prime \prime} \mathrm{E}$ and $33^{\circ} 3^{\prime} 12^{\prime \prime}-34^{\circ} 12^{\prime} \mathrm{N}$ (Fig. 1), on the upper reaches of the Yellow River in the southeastern portion of the Qinghai-Tibetan plateau. Its main types of vegetation are alpine meadow and swamp meadow. The mean annual temperature is $0.9^{\circ} \mathrm{C}$ and the mean annual precipitation $656.8 \mathrm{~mm}$ (Yang 1999).

In all three of the Qinghai-Tibetan plateau's regions, alpine wetland ecosystems constitute important sites for water conservation and the building of biodiversity, particularly in the headwaters regions of the Yangtze and Yellow rivers. Such ecosystems also represent a key ecological type in the China National Nature Reserve region of the Qinghai-Tibetan plateau (He and Zhao 2000; An 2003). Three main types of wetlands have been inventoried, namely "alpine swamp," "alpine lake," and "river" (Table 1). Alpine swamp wetlands, dominated by alpine swamp meadows, are most concentrated in the headwaters region of Yangtze River, whereas alpine lake wetlands mainly occur in Yellow River's headwaters region. The ratio of swamp and lake areas to the total area (swamp ratio) is greatest in the Zoige region ( $23 \%$ ), being only $5.1 \%$ and $5.5 \%$, respectively, in the headwaters regions of the Yangtze and Yellow Rivers. The similarly calculated wetland ratio [ (swamp + lake + river $) /$ total] is $8.6 \%$ and $8.2 \%$ for the headwaters of the Yangtze and Yellow Rivers, respectively.

The vegetation of these wetlands has some similarities: aquatic plant species include communities of Potamogeton distinctus A. Benn. and Hippuris vulgaris L. The dominant swamp vegetation species in the two headwaters regions include Kobresia tibetica Maxim. and Carex tibetica Franch (Li and Zhou 1998; Wang et al. 2001), while in the Zoige region, the dominant species include K. tibetica and Carex muliensis Tang. (Yang 1999; He and Zhao 2000). The soil types in the study region were mainly classified into Cryic 
Table 1 Typical alpine wetlands status and distribution of the Qinghai-Tibetan plateau

\begin{tabular}{|c|c|c|c|c|c|c|c|}
\hline Region and time & $\begin{array}{l}\text { Swamp } \\
\left(\mathrm{km}^{2}\right)\end{array}$ & $\begin{array}{l}\text { Lake } \\
\left(\mathrm{km}^{2}\right)\end{array}$ & $\begin{array}{l}\text { River } \\
\left(\mathrm{km}^{2}\right)\end{array}$ & $\begin{array}{l}\text { SR } \\
(\%)\end{array}$ & $\begin{array}{l}\text { WR/EWR } \\
(\%)\end{array}$ & $\begin{array}{l}\text { PR } \\
(\%)\end{array}$ & Main wetland river \\
\hline Yangtze R. headwaters (2000) & 5191.85 & 964.21 & 4289.07 & 5.1 & $8.6 / 10.6$ & 87.4 & Tongtian river (Yangtze) \\
\hline Yellow R. head-waters (2000) & 2141.71 & 1465.44 & 1733.53 & 5.5 & $8.2 / 10.0$ & 56.7 & Yellow River \\
\hline Zoige (2004) & 2302.89 & 17.97 & 93.79 & 22.6 & $23.6 / 26.8$ & Seasonal & Hei River \\
\hline
\end{tabular}

$W R$ wetland ratio: wetland area/total land area; $E W R$ effective wetland ratio: wetland area/total land area excluding upper mountain bare rock areas; $S R$ swamp ratio: swamp area/total land area; $P R$ permafrost ratio: permafrost area/total land area

Calcic Aridisols (Alpine steppe soil, as Cambisols in FAO/UNESCO taxonomy) and Mattic Cryic Cambisols (Alpine meadow siol, as Cambisols in FAO/UNESCO taxonomy).

Methods and datasets

\section{Data sets}

In the Yangtze and Yellow river headwaters areas, supported by a remote sensing interpretation marker database established on the basis of transect surveys, three sets of remote data, including 1967 aerophotographic data, as well as 1986 and 2000 satellite TM image data, were processed using ERDAS IMAGE and ARC/INFO softwares (with ArcView 3.1,ESRI Ltd.). Based on a 1:100,000 topographic base map, raw data was run through a series of treatments including $\mathrm{TM}[\mathrm{ETM}]$ radiation calibration, geometric rectification, UTM geographical coordinate image rectification, and topographic map $(1: 100,000)$ rectification. A remote sensing interpretation mark database consisting of 246 mark points of 11 types was established on the basis of transect surveys. so as to attain an accuracy of RMS $<1$ pixel.

Little intentional human disturbance of the Zoige region's wetlands has occurred since 1982; however, prior to 1985 , the Zoige region's wetlands had been degraded by peat extraction and artificial drainage of wetlands to improve pasturelands $(<1982)$ (He and Zhao 2000). Consequently, the wetlands changes since 1982 in the Zoige region were reasonably caused by climate change as similar as the Yangtze and Yellow River headwaters regions. The combination of remote sensing data (acquired in 1987, 1997, and 2004) and the field investigation data in 1967 and 1982

could be reasonably compared through time or across the region (i.e., with similar data from the Yangtze and Yellow River headwaters regions).

Six meteorological stations were located in the Yangtze and Yellow river headwaters areas and two in the Zoige region. These provided complete precipitation and air temperature data for the period of 1960-2005. Stream runoff depth at the outlet of the Yangtze and Yellow river headwaters' wetland areas was available for the period of 1960-2005, but for the Zoige wetland's outlet, runoff data were limited to the period of 1980-2005.

\section{Analysis of within-wetland spatial pattern changes}

Used to compare and analyze spatiotemporal shifts in wetland types, the variation in extent of land cover attributable to a specific wetland type, $P_{i}$, its rate of variation in time, $R_{i}$ and its extent of variation across subregions (Yellow, Yangtse, Zoige), $P_{k}$, were defined as (Liu et al. 2003; Wang et al. 2006a, b):

$$
\begin{aligned}
& P_{i}=100 \times\left[\left(L U_{i t 1}-L U_{i t 0}\right) / L U_{i t 0}\right] \\
& R_{i}=\frac{\left(L U_{i t 1}-L U_{i t 0}\right)}{L U_{i}} \times \frac{1}{T} \times 100 \%=P_{i} \times \frac{1}{T} \\
& P_{k}=\frac{\sum_{i=1}^{n}\left|L U_{k i t 1}-L U_{k i t 0}\right|}{L U_{k i t 0}} \times 100 \%
\end{aligned}
$$

where,

$i$

$k$ subscript represents wetland type, subscript represents the sub-region, 
$t 0, t 1$

$L U_{i t 0}$ and $L U_{i t 1}$

$L U_{k i t 0}$ and $L U_{k i t 1}$

subscript represents time of onset and end, respectively, of the time interval, $T$, under study,

represent the area of the $i$ th wetland type in the study region at the start and end of the study period, respectively, and

represent the area of the $i$ th wetland type in the $k$ th subregion at the start and end of the study period, respectively.

For assessing the discrete degree of spatial fragmentation of the wetland ecosystem, one can calculate the landscape fragmentation index and the degree of patch isolation, which can be viewed as potential influences on biodiversity. A wetland ecosystem's fragmentation index is calculated based on the landscape fragmentation formula of Wang et al. (2005, 2006a, b):

$C_{k i}=n_{k i} / L U_{k i}$

where,

$n_{k i}$ is the area of the patch number corresponding to $i$ th wetland type in the $k$ th sub-region,

$C_{k i} \quad$ is the fragmentation of the to $i$ th wetland type in the $k$ th sub-region, and

$L U_{k i}$ is the area of to $i$ th wetland type in the $k$ th sub-region.

The wetland's degree of patch isolation within the spatial distribution, $S_{k i}$, can be determined according to the method developed in landscape ecology (Wang et al. 2005, 2006a, b).

$$
S_{k i}=\left(0.5 \sqrt{\frac{n_{k i}}{L U_{k i}}}\right) /\left(L U_{k i} / L U_{k}\right)
$$

\section{Relationship between climatic factors and changes in wetland area}

For the Yangtze and Yellow rivers' headwaters regions, analysis of remote sensing data and historical records yielded vegetative cover distribu-

tions for the years 1967, 1986, 2000, whereas for the Zoige region cover distributions were developed for 1967, 1982, 1989, 1997, and 2004. The period of 1967 to 2004 was divided into two interpolation intervals for the headwater regions of the Yangtze and Yellow rivers (1967-1986, 1987$2000 ; j=1-2)$, and four such intervals for the Zoige region (1967-1982, 1983-1987, 1988-1997, and 1997-2004; $j=1-4)$. The extent of cover provided by each of two wetland types, alpine swamp and alpine lake, was correlated against climate change parameters to obtain a relationship extending between 1967 and 2004. Regional changes in wetland area on the Qinghai-Tibetan plateau were mainly driven by population dynamics, economic policies, and their interactions (He and Zhao 2000; Wang et al. 2001). In this study, a population-based piecewise linear interpolation method was developed to simulate the dynamics of wetland area change, using a 3-year moving average as the weight of the linear interpolation:

$$
L U_{i t}=L U_{i, t-1}+r_{j t} \Delta L U_{i j}
$$

where,

$j$

$r_{j t}$

$\Delta L U_{i j}$

$L U_{i t}, L U_{i, t-1}$

is the date interval number, is the mean population growth/ economic policy weighing factor at year $t$ within the $j$ th interval.

is the difference in wetland area of the $i$ th region between the beginning and end of the $j$ th interval; are the areas of the $i$ th wetland type in the study region, at times $t$ and $t-1$, respectively.

\section{Results and discussion}

Changes in the spatial distribution of alpine wetland ecosystems

A plot of the changes in the spatial distribution of wetland ecosystems in the source region of the Yangtze River between 1967 and 2000 (Fig. 2a) shows that prior to the mid-1980s, changes in the headwaters regions' wetland ecosystems, mainly limited to the northeastern portion of the region, 

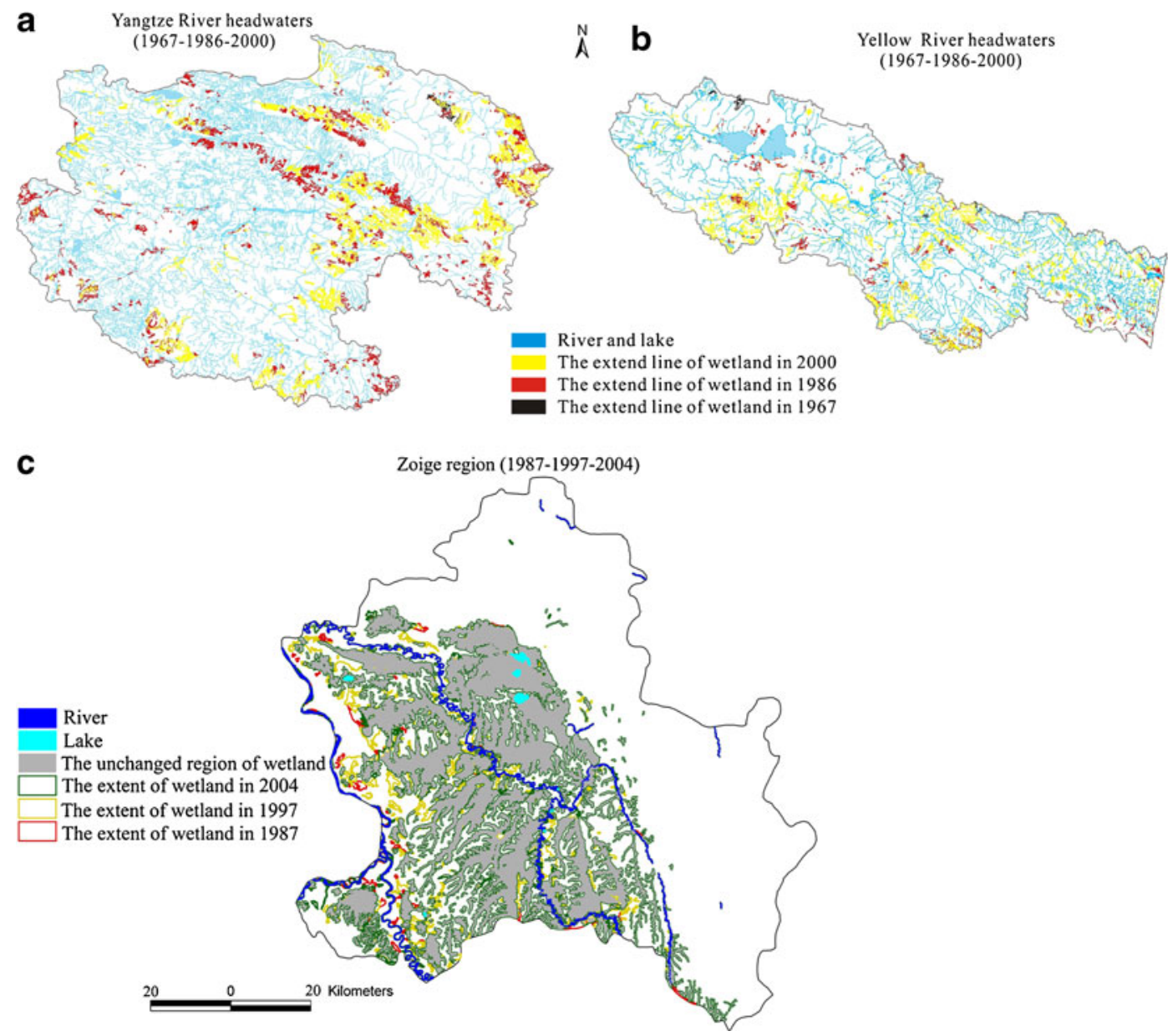

Fig. 2 Variation in the spatial pattern of typical alpine wetlands in the Qinghai-Tibetan plateau region

were minor. From 1989 to 2000, dramatic changes in the spatial distribution of wetland ecosystems took place, such that by the year 2000, a large area of wetlands had disappeared from the central and southeastern portions of the region. The situation was similar in the Yellow River headwaters region (Fig. 2b), where the small changes in wetland distribution were mainly limited to the northern and middle mountain regions between 1967 and 1986, whereas between 1986 and 2000, the wetland distribution changed significantly over almost the entire region. This change was particularly evident in the wetlands of Maduo county, including the region to the north where two lakes disappeared. As for the Zoige region's wetland, shifts in its spatial distribution were investigated for the period of
1989 to 2004, when no large-scale anthropogenic disturbances occurred. Shifts in wetland distribution were far smaller between 1989 and 1997 than between 1997 and 2004 period (Fig. 2c), when the loss of wetlands occurred both in the western and southern portions of the region.

\section{Changes in spatial distribution of alpine swamp wetland}

The area of alpine swamp wetlands typical of the Qinghai-Tibetan plateau and predominantly located in the Yangtze River's headwaters region, decreased by 29\% (0.93\% year $\left.{ }^{-1}\right)$ between 1967 and 2000 (Table 2). Roughly $96 \%$ of this loss took place between 1986 and 2000 period, occurring 
Table 2 Changes in spatial distribution characteristics of alpine wetland systems of the Qinghai-Tibetan plateau

\begin{tabular}{|c|c|c|c|c|c|c|c|c|c|}
\hline \multirow[t]{2}{*}{ Index } & & \multicolumn{3}{|l|}{$P_{i}$} & \multicolumn{3}{|l|}{$R_{i}$} & \multirow[t]{2}{*}{ Area $\mathrm{Km}^{2}$} & \multirow[t]{2}{*}{$P_{k}$} \\
\hline & & Swamp & River & Lake & Swamp & River & Lake & & \\
\hline \multirow[t]{3}{*}{ Yangtze source region } & $1967-1986$ & -1.05 & -0.37 & -0.82 & -0.06 & -0.02 & -0.05 & -101.54 & 0.80 \\
\hline & $1986-2000$ & -28.11 & -0.33 & -10.64 & -1.87 & -0.02 & -0.71 & -2159.28 & 17.13 \\
\hline & $1967-2000$ & -28.87 & -0.70 & -11.37 & -0.93 & -0.02 & -0.37 & -2260.82 & 17.79 \\
\hline \multirow[t]{3}{*}{ Yellow source region } & 1967-1986 & -0.17 & -0.44 & -1.44 & -0.01 & -0.03 & -0.08 & -35.11 & 0.59 \\
\hline & $1986-2000$ & -13.41 & -9.03 & -5.28 & -0.89 & -0.60 & -0.35 & -585.47 & 9.88 \\
\hline & $1967-2000$ & -13.55 & -9.43 & -6.64 & -0.44 & -0.30 & -0.21 & -620.58 & 10.41 \\
\hline \multirow[t]{3}{*}{ Zoige region } & 1987-1997 & -2.93 & -17.29 & -11.55 & -0.16 & -0.96 & -0.64 & -97.53 & 3.51 \\
\hline & 1997-2004 & -10.46 & 13.27 & -9.82 & -1.49 & 1.90 & -1.40 & -260.38 & 9.72 \\
\hline & 1987-2004 & -13.08 & -6.31 & -20.24 & -0.87 & -0.42 & -1.35 & -357.91 & 12.89 \\
\hline
\end{tabular}

at a rate of $1.87 \%$ year $^{-1}$. The area of swamp wetland in the Yellow River's headwaters decreased by $13.55 \%$ between 1967 and $2000(0.44 \%$ year $^{-1}$, i.e. roughly half the rate of the Yangtze headwaters region), with the majority of the drop occurring between 1986 and 2000 period.

The changes in wetland distribution in the Zoige region since 1967 can be divided into two stages: the period before 1982 when the region was submitted to intense human disturbance and the period from 1982 onwards when, besides grazing, disturbance from human activities was minimal, or at worst controlled. In the earlier period (1970s), swamp wetlands were drained to increase grazing pasture, their area decreasing by about $52 \%$, while the area of lake wetlands decreased by $80 \%$ between 1967 and 1982 (Fig. 3; Yang 1999; Wang et al. 2005). After 1982, changes in the area of wetland ecosystems were comparable to those occurring in the headwaters regions of the Yangtze and Yellow Rivers. Between 1982

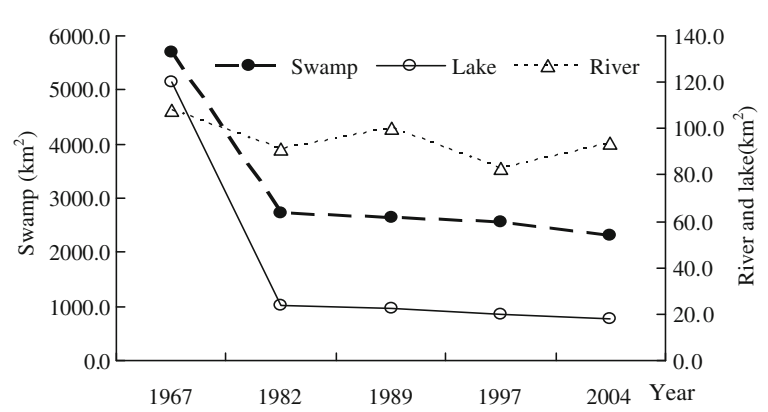

Fig. 3 Wetland area decrease from 1967-2004 in the Zoige region Qinghai-Tibetan plateau and 2004 period the area of swamp wetland in the Zioge region decreased by $15.8 \%$, split roughly 60:40 between the periods of 1997-2004 and 19821997, respectively (Table 2).

\section{Changes in lake and river areas}

Between 1967 and 2000, the area of wetland lakes in the Yangtze and Yellow River headwaters regions decreased by $11.4 \%$ and $6.6 \%$, respectively, $93 \%$ and $78 \%$ of which decline occurred after 1986 (Fig. 4b). Between 1982 and 2004, the area of wetland lakes in the Zoige region decreased by $24 \%\left(0.26 \mathrm{~km}^{2}\right.$ year $\left.^{-1}\right), 84 \%$ of which decline occurred after 1987 (Table 2).

Within the Yangtze and Yellow River headwaters regions, losses in lake area were distinctly different between interior and exterior lakes (Fig. 4a), the latter of which accounted for $62.3 \%$ and $84.7 \%$, respectively, of each region's total lake area (1967). Between 1967 and 2000, the area of interior and exterior lakes within the Yangtze River headwaters region decreased by 54.6 and $66.5 \mathrm{~km}^{2}$, respectively, representing decreases of $13.3 \%$ and $9.8 \%$ in the respective lakes' areas. This resulted in the loss of 360 lakes or $17.5 \%$ of those existing in 1967. Between 1967 and 2000, the area of interior and exterior lakes in the Yellow River headwaters region decreased by 34.1 and $70.2 \mathrm{~km}^{2}$, respectively, representing decreases of $14.2 \%$ and $5.3 \%$ in the respective lakes' areas. The loss of interior lake wetlands by areas was significantly greater than that of exterior lake wetlands. The effects of wetland variation on hydrology regimes were led to an alteration in hy- 


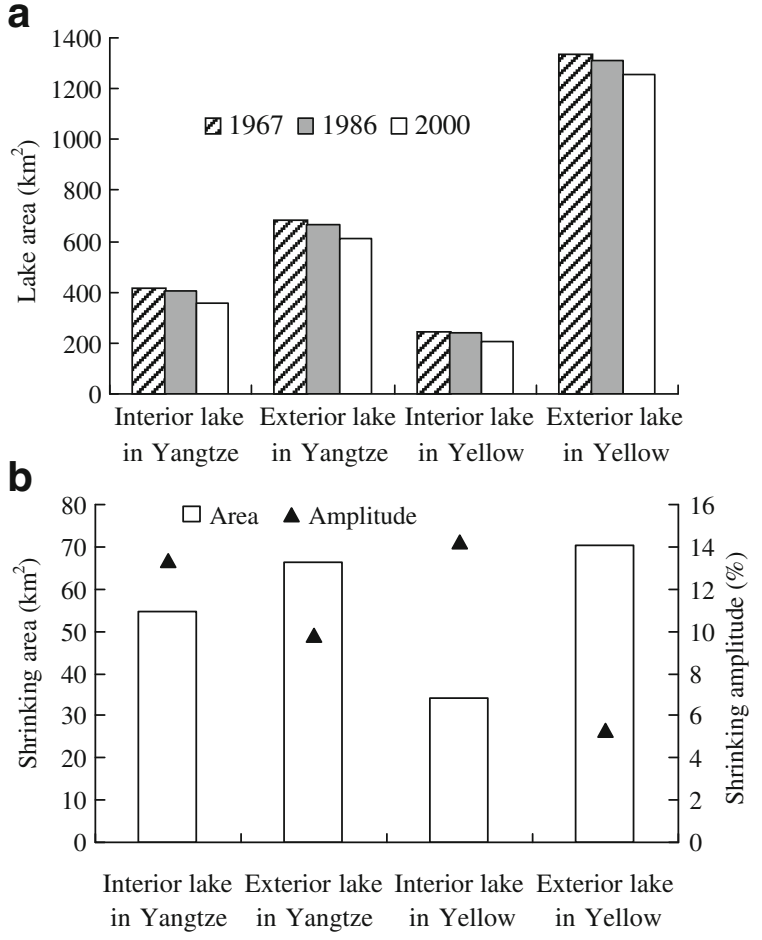

Fig. 4 The interior and exterior lakes' distribution a and changes $\mathbf{b}$ in the Yangtze and Yellow Rivers headwaters regions within the Qinghai-Tibetan plateau

drological process in alpine wetland-bearing river basins, the severer the degree of degradation of swamp wetlands, and the more significant the changes in associated hydrological processes. Under conditions of an evident increase in precipitation during the January-February drought period, the Qinghai-Tibetan plateau's alpine wetland ecosystems runoff for the same period showed a decreasing trend.

The area of river wetlands in the Yangtze River headwaters region decreased by only $0.7 \%$ over the period of 1967-2000, while that of the Zioge region showed no clear trend (Table 2, Fig. 3). The situation was quite different in the Yellow River headwaters region, where the area of river wetlands decreased continuously between 1967 and 2000 , reaching a total decline of $9.4 \%$ or $180.6 \mathrm{~km}^{2}$, which exceeded that of lake wetlands for the region.

\section{Changes in spatial patterns of wetland ecosystems}

Swamp wetlands' fragmentation and patch isolation indexes were greatest for the Yellow River headwaters region and least for the Zioge region, indicating such wetlands' distribution to be relatively concentrated in the Zoige region and relatively scattered in the Yellow River headwaters region (Table 3). For lake wetlands, the fragmentation index was greatest for the Yangtze River headwaters region, and patch isolation greatest in the Zoige region, indicating that in the former case wetland lakes were well scattered in small lake groups, while in the latter case they consisted of a few widely scattered large lakes. In the Yellow River headwaters region, wetland lakes were closely spaced and relatively concentrated. Such a distribution pattern occurring for the Yellow River headwaters' swamp wetlands and Yangtze River headwater's lake wetlands rendered them more sensitive and fragile to disturbance by environmental changes.

The level of patch isolation for the Yellow River headwaters and Zoige regions' alpine swamps increased continuously from 1967 onwards, particularly after the mid-1980s (Table 3). The trend in lake wetlands was towards large lakes, especially after the mid-1980s when many scattered small lakes dried up or disappeared; therefore, lake wetlands' levels of fragmentation
Table 3 Indexes of spatial pattern changes for typical alpine wetlands of the Qinghai-Tibetan plateau

\begin{tabular}{|c|c|c|c|c|c|c|c|c|c|c|}
\hline \multicolumn{2}{|c|}{ Parameter/wetland type } & \multicolumn{9}{|c|}{ Region/Year } \\
\hline & & \multicolumn{3}{|c|}{ Yangtze headwaters } & \multicolumn{3}{|c|}{ Yellow headwaters } & \multicolumn{3}{|c|}{ Zoige region } \\
\hline & & 1967 & 1986 & 2000 & 1967 & 1986 & 2000 & 1987 & 1997 & 2004 \\
\hline \multirow[t]{2}{*}{ Fragmentation } & Swamp & 0.15 & 0.15 & 0.11 & 0.86 & 0.87 & 0.94 & 0.10 & 0.11 & 0.15 \\
\hline & Lake & 1.89 & 1.91 & 1.76 & 0.52 & 0.52 & 0.32 & 0.49 & 0.45 & 0.45 \\
\hline \multirow[t]{2}{*}{ Patch isolation } & Swamp & 0.25 & 0.25 & 0.23 & 0.72 & 0.72 & 0.76 & 0.16 & 0.17 & 0.2 \\
\hline & Lake & 2.35 & 2.37 & 2.18 & 0.70 & 0.71 & 0.54 & 3.88 & 3.90 & 3.87 \\
\hline
\end{tabular}


and patch isolation tended to decrease. Unlike the changes in these regions, swamp and lake ecosystems in the Yangtze River headwaters region showed decreases in both fragmentation index and patch isolation index, suggesting that the degradation of wetlands led to the disappearance of some small scattered lakes.

In summary, (1) while, from 1967-2004, the Qinghai-Tibetan plateau witnessed the degradation of alpine wetland ecosystems, close to two thirds of this degradation occurred after 1985 , when the rate of degradation began to climb, (2) the degradation of alpine wetland ecosystems was dominated by that of alpine swamps, which accounted for $93 \%, 54 \%$, and $97 \%$ of the total decrease in wetland area in the Yangtze River headwaters, Yellow River headwaters, and in the Zoige region, respectively. The dwindling of interior wetland lakes was severest in the Yangtze and Yellow River headwaters regions, (3) the degradation of wetland ecosystems led to changes in their pattern of spatial distribution. In the Yellow River headwaters and Zoige regions, the extent of fragmentation and patch isolation of swamp wetland increased continuously, whereas in the Yangtze River headwaters region, wetland ecosystem degradation manifested itself in the disappearance of scattered small wetland patches and the spatial concentration of wetland ecosystems.

Correlations between wetland degradation and climate variables

Alpine wetland ecosystems are sensitive to climate change. To explore the correlation between wetland area and climate change, the climate variables of the mean annual air temperature, annual precipitation, mean air temperature, and precipitation during the growing season (April-Sept.) were selected.

In the Yangtze River headwaters region, wetland area correlated strongly with growing season air temperature $(R=0.73, P \leq 0.001$; Fig. 5a) and relatively weakly with mean annual air temperature $(R=0.43, P=0.044)$. In contrast, wetland area was more weakly correlated with annual precipitation $(R=0.25, P=0.38)$ and mean

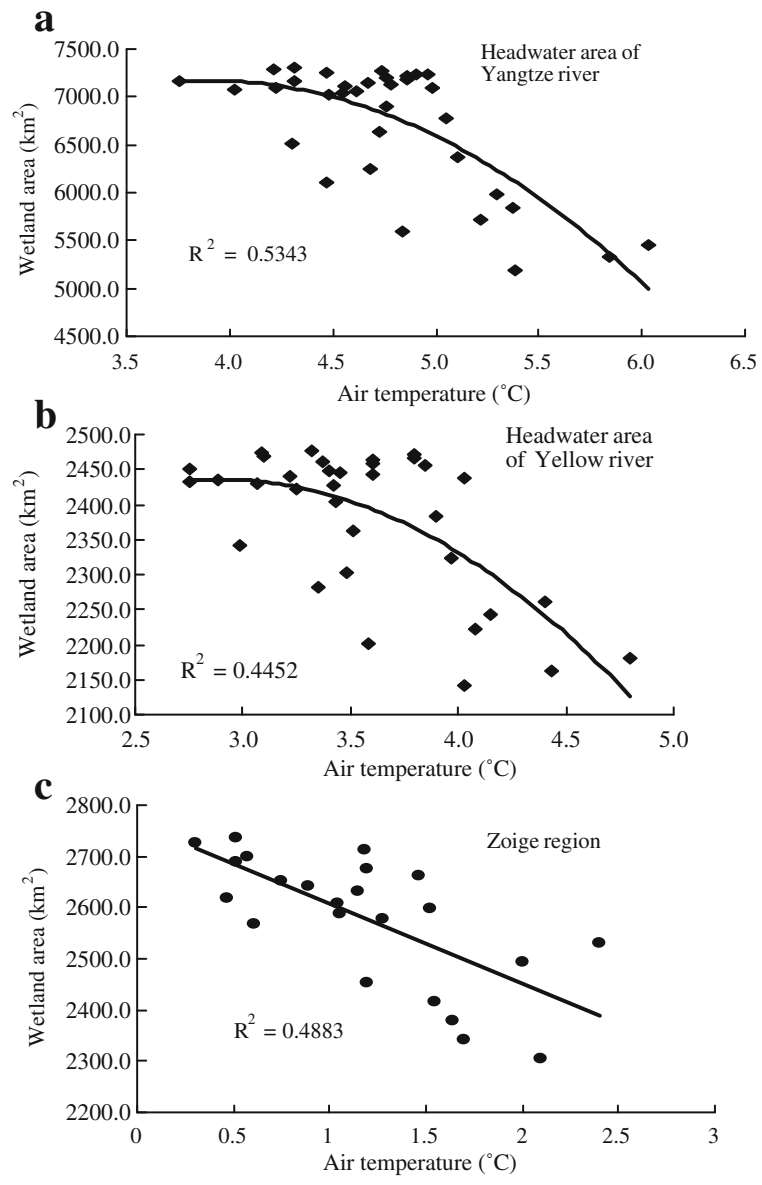

Fig. 5 Correlative relationships between alpine wetland area and climate variables

growing season precipitation $(R=0.32, P=0.19)$. In the Yellow river headwaters region, wetland area closely correlated with growing season air temperature ( $R=0.67, P<0.001$; Fig. 5 b) and to a lesser extent with mean annual air temperature $(R=0.47, P=0.021)$. Wetland area was more weakly correlated with annual precipitation ( $R=0.21, P=0.48$ ) and mean growing season precipitation ( $R=0.30, P=0.23$ ). For the Zoige region, wetland area was strongly correlated with both growing season air temperature $(R=0.82$, $P<0.001)$ and the mean annual air temperature ( $R=0.71, P<0.001$; Fig. 5c), but no significant correlation occurred with precipitation. However, the nature of the relationship between the area of alpine wetlands and air temperature differed according to region: in the Yangtze and Yellow River headwaters regions, the relationship was 
quadratic, while it was linear for the Zoige region (Fig. 5).

These strong wetland area-air temperature relationships demonstrate that the Qinghai-Tibetan plateau's alpine wetlands were strongly influenced by air temperature changes, particularly during the vegetation's growing season. Alpine wetland degradation (loss of area) was strongly linked to the rise in growing season air temperature over the past 40 years. The fact that the degree of inverse correlation between alpine wetland area and air temperature in the Yangtze and Yellow Rivers headwaters regions was less than that in the Zoige region suggests that the permafrost present in the former regions, but largely absent in the latter, had a great influence on the growth and development of alpine swamp and meadow ecosystems (Zhao et al. 2000; Wang et al. 2006a, b). The permafrost layer can effectively prevent surface water and soil water from downward seepage, leading to greater root zone soil moisture. Numerous observations and studies (Wang et al. 2006a, b; Zhou 2001; Zhao et al. 2000) showed that there is a significant statistical correlation between vegetative cover and thickness of the active soil layer of permafrost in alpine meadow and alpine swamp meadow ecosystems. As the thickness of the active layer increases, the vegetative cover of alpine swamp (including alpine meadows) decreases. Over the last 30 years, the warming climate has raised the temperature of the upper 0-0.40-m layer of the Qinghai-Tibetan plateau's permafrost soils by $0.2-0.3^{\circ} \mathrm{C}$, on average (Wang 1998; Wu et al. 2001). Raising of the topsoil's temperature has expanded the thawed soil area, thickened the seasonal thawing layer, or even led to complete disappearance of permafrost (Zhao et al. 2000; Wang et al. 2001). This degradation of the permafrost has, in turn, significantly impacted alpine wetland ecosystems in the Yangtze and Yellow River headwaters regions.

\section{Conclusion and discussion}

Degradation of alpine wetlands in the QinghaiTibetan plateau has progressed since the 1960s to become a widespread phenomenon. Since the 1960 s, wetlands area had decreased by over $10 \%$, particularly swamp wetland in the Yangtze River headwaters region, which declined by $18 \%$ between 1986 and 2000. Degradation of alpine wetland ecosystems in the Yellow River headwaters and Zoige regions led to fragmentation in their spatial distribution and a continuous increase their degree of patch isolation, resulting in their greater sensitivity and fragility in the face of climatechange-induced disturbances. The fragmentation and isolation of habitats poses a severe and potential threat to the biodiversity of the alpine wetland.

The widespread degradation of the alpine wetland system on the Qinghai-Tibetan plateau is closely linked to regional climate warming. Between 1960 and 2000, the region's mean annual air temperature rose by $0.19-0.23^{\circ} \mathrm{C} \mathrm{decade}^{-1}$ and after 1982 by $0.46-0.53^{\circ} \mathrm{C}$ decade $^{-1}$; however, over the latter period, the precipitation was stable or increased only slightly. Given the presence of permafrost in the Yangtze River headwaters region, the temperature increase and corresponding permafrost changes had a synergetic degrading influence on alpine wetland ecosystems.

Changes in alpine wetland's hydrological functionality directly led to an alteration in hydrological process in alpine wetland-bearing river basins. The greater a basin's wetland ratio, the severer the degree of degradation of swamp wetlands, and the more significant the changes in associated hydrological processes. The impacts of alpine wetland systems' degradation on the runoff from the Yangtze and Yellow rivers are the key science issue required to deeper research in future.

Acknowledgements This study was funded by he national key scientific plan (973) (No.2007CB411504) and the Natural Science Foundation of China (No. 40925002).

Open Access This article is distributed under the terms of the Creative Commons Attribution Noncommercial License which permits any noncommercial use, distribution, and reproduction in any medium, provided the original author(s) and source are credited.

\section{References}

An, S. (2003). Wetland ecosystem-utilization and protection of wetland resources optimization model. Beijing: Chemical Industry Press. 
Bullock, A., \& Acreman, M. (2003). The role of wetlands in the hydrological cycle. Hydrology and Earth System Sciences, 7(3), 358-389.

Conly, F. M., \& Van Der Kamp, G. (2001). Monitoring the hydrology of Canadian prairie wetlands to detect the effects of climate change and land use changes. Environmental Monitoring and Assessment, 67, 195215.

Cui, B., \& Yang, Z. (2006). Wetlands science. Beijing: Beijing Normal University Press.

DeFries, R., \& Eshleman, K. N. (2004). Land-use change and hydrologic processes: A major focus for the future. Hydrological Processes, 18, 2183-2186.

Gong, P., et al. (2010). China's wetland change (1990-2000) determined by remote sensing. Science in China Series D-Earth Sciences, 40(6), 768-775.

He, C., \& Zhao, K. (2000). Influence of human activities on the Mire in Zoige Plateau and countermeasure. Scientia Geographica Sinica, 20(5), 444-449.

Jorgenson, M. T., Racine, C. H., Walters, J. C., \& Osterkamp, T. E. (2001). Permafrost degradation and ecological changes associated with a warming in Central Alaska. Climatic Change, 48, 551579.

Lang, H. (1999). Wetland vegetation in China. Beijing: Science.

Li, S., \& Wu, T. (2005). The relation between ground-air temperatures in Qinghai-Tibetan Plateau. Journal of Glaciology and Geocryology, 27(5), 1-6.

Li, W., \& Zhou, X. (1998). Ecosystems of Qinghai-Tibetan plateau and approach for their sustainable management. Guangzhou: Guangdong Science \& Technology Press.

Liu, J., Liu, M., \& Zhuang, D. (2003). Study on spatial pattern of land-use change in China during 19952000. Science in China Series D-Earth Science, 46(4), 373-384.

McGuire, A. D., Sturm, M., \& Chapin III, F. S. (2003). Arctic transitions in the land-atmosphere system (ATLAS): Background, objectives, results, and future directions. Journal of Geophysical ResearchAtmospheres, 108, 2. doi:10.1029/2001JD000236.

Price, J. S., Branfireun, B. A., Waddington, J. M., \& Devito, K. J. (2005). Advances in Canadian wetland hydrology, 1999-2003. Hydrological Processes, 19, 201-214.

Price, J. S., \& Schlotzhauer, S. M. (1999). Importance of shrinkage and compression in determining water storage changes in peat: The case of a mined peatland. Hydrological Processes, 13, 2591-2601.

Price, J. S., \& Waddington, J. M. (2000). Advances in Canadian wetland hydrology and biogeochemistry, 1995-1998. Hydrological Processes, 14, 1579-1589.

Qin, D. (2002). Evaluation of the environmental evolution in west China. Beijing: Science.
Quinton, W. L., \& Marsh, P. (1999). A conceptual framework for runoff generation in a permafrost environment. Hydrological Processes, 13, 2563-2581.

Reeve, A. S., Siegel, D. I., \& Glaser, P. H. (2000). Simulating vertical flow in large peatlands. Journal of Hydrology, 227, 207-217.

Rodriguez-Iturbe, I. (2000). Ecohydrology: A hydrological perspective of climate, soil and vegetation dynamics. Water Resources Research, 36(1), 3-9.

Wang, G., Cheng, G., \& Shen, Y. (2001). Research on ecological environmental change in the source regions of Yangtze-Yellow Rivers and their integrated protection. Lanzhou: Lanzhou University Press.

Wang, G., Li, Y., \& Chen, L. (2006a). Impacts of permafrost changes on alpine ecosystem in QinghaiTibetan plateau. Science in China Series D-Earth Sciences, 49(11), 1156-1169.

Wang, G., Liu, J., \& Chen, L. (2006b). Comparison of spatial diversity of land use changes and the impacts on two typical areas of Heihe River Basin. Acta Geographica Sinica, 61(4), 339-348.

Wang, G., Liu, J., Jumpei, K., \& Chen, L. (2007a). Effects of land-use changes on hydrological processes in the Middle Basin of the Heihe River, Northwest China. Hydrological Processes, 21(10), 1370-1382.

Wang, G., Wang, Y., \& Li, Y. (2007b). Influences of alpine ecosystem responses to climatic change on soil properties on the Qinghai-Tibetan plateau, China. Catena, 70(3), 506-514. doi:10.1016/j.catena2007.01.001.

Wang, S. (1998). Discussion on the permafrost degradation and the changes of the permafrost environment of Qinghai-Xizang plateau [in Chinese with English abstract]. Journal of Advances in Earth Science, 13(Suppl), 65-73.

Wang, Y., Zhao, Z., \& Qiao, Y. (2005). Characteristics of the climatic variation in Zoige in the past 45 years and its effects on the eco-environment in the area. Journal of Geomechanics, 11(4), 328-332.

Wassen, W. J., \& Grootjans, A. P. (1996). Ecohydrology: An interdisciplinary approach for wetland management and restoration. Journal of Vegetation, 126, 1-4.

Wu, Q., Li, X., \& Li, W. (2001). The response model of permafrost along the Qinghai-Tibetan Highway under climate change [in Chinese with English abstract]. Journal of Glaciology and Geocryolog, 23(1), 1-6.

Yang, Y. (1999). Ecological environment deterioration, mire degeneration and their formation mechanism in the Zoige plateau. Journal of Mountain Research, 17(4), 318-323.

Zhao, L., Chen, G., \& Cheng, G. (2000). Permafrost: Status, variation and impacts. In D. Zheng, Q. Zhang, \& H. Shao (Eds.), Mountain geoecology and sustainable development of the Tibetan Plateau (pp. 113-137). Netherlands: Kluwer.

Zhou, X. (2001). China meadow. Beijing: Science. 